\title{
Correlation between Self-Efficacy and English Performance
}

\author{
https://doi.org/10.3991/ijet.v15i08.13697 \\ Yinchun Chen \\ Shanghai Jianqiao University, Shanghai, China \\ chenyc@gench.edu.cn
}

\begin{abstract}
Self-efficacy may affect our behaviours, thoughts and emotions. The students with strong self-efficiency tend to have good autonomous learning ability. However, there is little report on the correlation between self-efficacy and English performance. To make up for the gap, this paper explores the influence of self-efficacy on English performance based on the theories on self-efficacy. Specifically, a questionnaire survey was carried out among male and female students in three grades, covering all aspects of English learning (e.g. listening, speaking, reading and writing). The collected data were analysed statistically on the SPSS. The results show that self-efficacy influences the selection of environment and behaviour; the students with strong self-efficacy can flexibly use various cognitive and learning methods, and achieve excellent selfmanagement and regulation; the students with good English performance have high self-efficacy scores, revealing a positive correlation between self-efficacy and English performance. The research findings lay a theoretical basis for improving English performance based on self-efficacy.
\end{abstract}

Keywords—English performance, self-efficacy, behavioural efficacy, ability efficacy

\section{Introduction}

It is a difficult task to learn English as a foreign language. The learning methods for the mother tongue are often not applicable to English. Neither is rote memorization a suitable way for English learning. The students may have invested lots of time, energy and effort, but failing achieve a desired English performance [1-2].

The difficulty in English learning, coupled with the growing importance of the language, poses a tremendous pressure on students. As a result, many of them have gradually lost interest and confidence in English learning. Thus, negative emotions continue to accumulate over the time [3].

In the learning process, the students with high self-efficacy have relatively few negative emotions [4]. Self-efficacy is a set of beliefs that individuals hold about their motivation, cognitive ability and action capacity to achieve goals. These beliefs greatly influence the effect of English learning, because the English performance of a student hinges on his/her mood and attitude in learning [5]. 
In English learning, the self-efficacy of a student is manifested as the belief in his/her own ability to learn English. As mentioned before, students with high self-efficacy tend to be optimistic and willing to learn, despite the setbacks and challenge-es in the learning process. On the contrary, students with low self-efficacy are not confident, and fearful of difficulties in learning [6].

By improving self-efficacy, it is possible to regulate the behaviours, habits and attitudes of English learners, and enhance English performance continuously in a comprehensive manner [7]. One of the key aspects of self-efficacy is psychological self-regulation, which promotes the effect of cognitive strategies in English learning [8].

Studies have shown that self-efficacy is composed of an individual's attitudes, abilities, and cognitive resources. These components may vary with genders, ages, education levels, and regions [9]. Based on self-efficacy theory, this paper probes deep into the impacts of self-efficacy on the English performance of second language learners, and explores the relationship between self-efficacy and the English performance.

\section{The Relationship between Self-efficacy and Learning Ability}

\subsection{Theoretical basis of self-efficacy}

Self-efficacy is a form of thinking. It plays an important role in the individuals' judgment of their own abilities and self-regulation process [10]. The self-efficacy in learning reflects the individual's judgment of ability and belief in academic aspects, which is affected by personal learning ability, teachers or parents' expectations and emotions etc. It's also the learner's judgment of their ability to complete learning tasks and the confidence of achieving a goal [11]. Fig 1 shows the ternary interaction causality diagram. A ternary interaction is formed between the individual's subjective factors (e.g., cognition, emotion, and thinking), the environment, and the behaviour. Fig 2 shows the hierarchy of individual needs. The hierarchy of human needs is divided into five levels from low to high, which are physiological needs, security needs, belonging and love needs, respect needs, and self-actualization needs; the first three needs can be regarded as real needs, and the last two are high-level needs, that is, growth needs. The low-level needs must be met before high-level needs [12]. Under the influence of self-efficacy, the behaviour subjects adjust their ability, thinking mode, and behaviour intensity. Throughout this entire process, the action mechanism of self-efficacy is achieved by thinking, selection, motivation, and physical and mental reactions of the subjects [13].

The theoretical levels of self-efficacy are divided into the hierarchy of needs, achievement motivation, self-efficacy, achievement goals, self-determination and selfworth [14]. In the learning process, the satisfaction degree of individual psychological needs will determine the energy and nature of learning motivation. Self-efficacy complements English learning motivation and attitude from a new perspective [15]. 


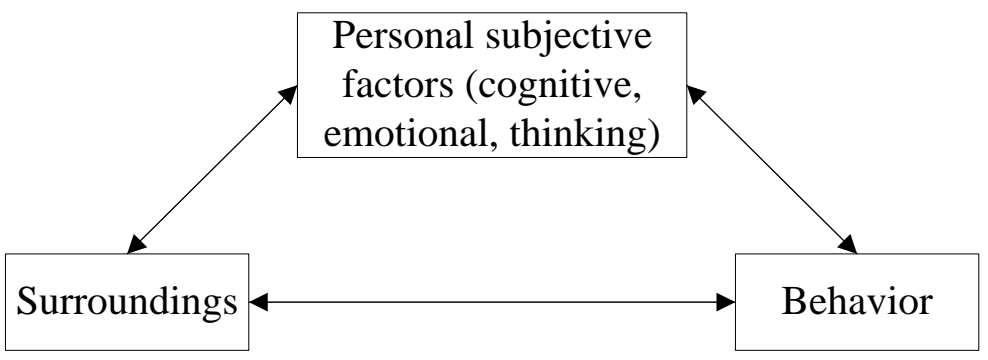

Fig. 1. Ternary interactive causality diagram

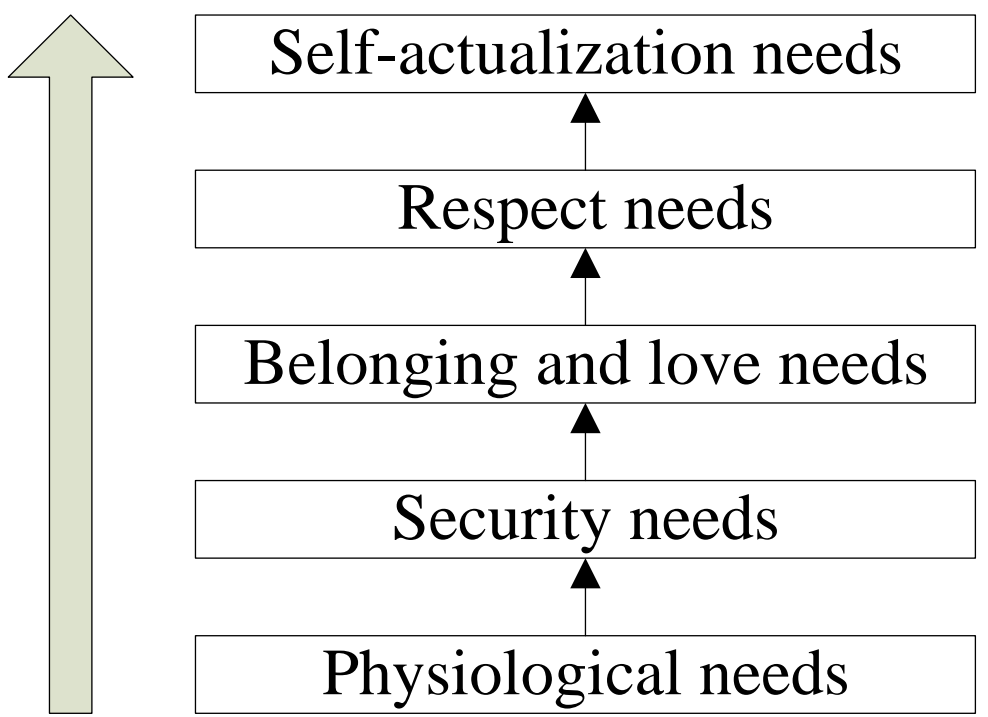

Fig. 2. Hierarchy of individual needs

\subsection{The relationship between students' self-efficacy and academic performance}

Some researchers have explored the relationship between self-efficacy and English reading ability, finding that through the proper use of their relationship in the training, the students can improve their level of self-efficacy, the use of reading strategies and English reading performance [16]. Fig 3 shows the self-efficacy mechanism, including selection process, cognitive process, incentive process, and emotional process. Selfefficacy affects the selection of environment and behaviour; beliefs of self-efficacy affect cognitive processes in a variety of ways; self-efficacy plays a major role through the thinking process accompanied by motivation factors or processes. There is a certain relationship between students' English autonomous learning, academic performance and self-efficacy. Some studies have found that there is a significant correlation between student autonomy, learning strategies, learning motivation, and self-regulation and English learning self-efficacy $[17,18]$. Under normal circumstances, students with 
high self-efficacy can flexibly use a variety of cognitive strategies, learning strategies, and self-management and regulation.

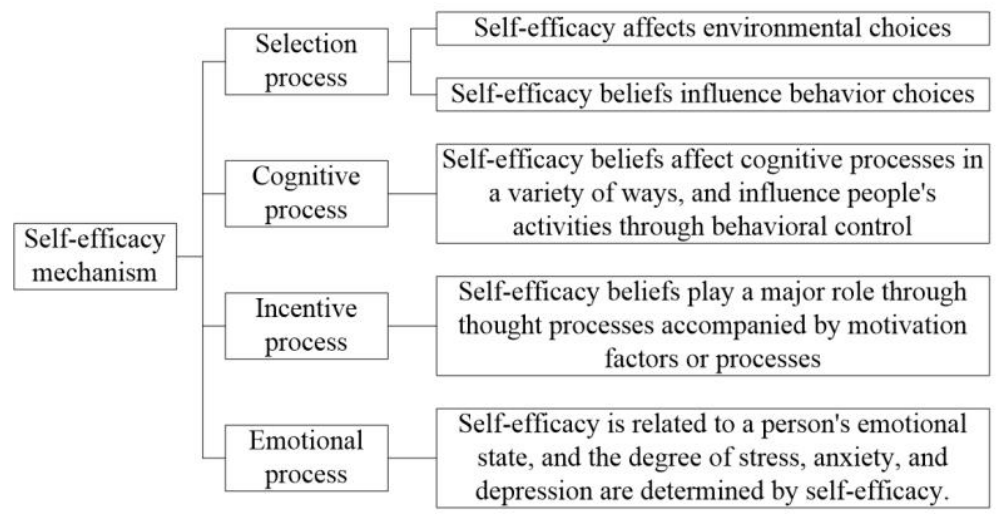

Fig. 3. Self-efficacy mechanism

\section{$3 \quad$ Research Subjects and Methods}

At present, research on the impact of self-efficacy on English learning is a very hot topic, but the overall research is not deep enough. Also, there have been few researches on the relationship between self-efficacy and English performance. In this paper, the questionnaire surveys and practical statistical analysis methods were adopted to deeply explore the high school students' English learning autonomy, self-efficacy score and the relationship between English performance and self-efficacy. Learning autonomy was scored on a 100-point scale and self-efficacy was scored on a 5-point scale. Table 1 lists the basic information of the test subjects selected from high school students in a middle school in Xiaogan, Hubei province. A total of more than 240 questionnaires were issued, and 216 were valid questionnaires were recovered, including 120 boys and 96 girls in three grades.

Table 1. Basic information of subjects

\begin{tabular}{|l|l|c|c|}
\hline \multicolumn{1}{|c|}{ Type } & \multicolumn{1}{|c|}{ Category } & Quantity & Percentage/\% \\
\hline \multirow{3}{*}{ Sex } & Male & 120 & $55.56 \%$ \\
\cline { 2 - 4 } & Female & 96 & $44.44 \%$ \\
\hline \multirow{3}{*}{ Class } & Senior grade one & 66 & $30.56 \%$ \\
\cline { 2 - 4 } & Senior grade two & 87 & $40.28 \%$ \\
\cline { 2 - 4 } & Senior grade three & 63 & $29.17 \%$ \\
\hline \multirow{3}{*}{ Academic record } & Excellent & 49 & $22.69 \%$ \\
\cline { 2 - 4 } & Medium & 125 & $57.87 \%$ \\
\cline { 2 - 4 } & Difference & 42 & $19.44 \%$ \\
\hline
\end{tabular}

The selected measurement tool was the questionnaire of English self-efficacy, covering English listening, speaking, reading and writing. The survey was conducted with 
the cooperation of the teacher in the class as a unit, while the participants knew nothing about the purpose of the survey file, in order to ensure the authenticity and reliability of the questionnaire. Data analysis was performed using SPSS software.

\section{$4 \quad$ Research Results and Analysis}

\subsection{Analysis for English learning autonomy of high school students}

The English learning is the process of actively forming a cognitive structure through the recognition of English forms. Autonomy can be regarded as a sense of self-efficacy in the cognitive process, which affects students' learning motivation, behaviour and performance. Students' acceptance of English knowledge can only be accomplished by their own construction. Learners actively synthesize, reorganize, and transform existing knowledge, to obtain new information, things, or achieve personal significance. The self-efficacy is improved when the learners are constantly acquiring language input that is higher than their current language ability. Only when students are exposed to language information that is higher than their current language level will they have autonomy.

The autonomy of English learning includes English learner autonomy, English learning goal setting, English learning motivation, English learning strategies and English learning evaluation. Fig 4 shows the English learning autonomy scores of senior high school students. It can be clearly seen that students scored the highest in English learning goal setting, followed by English learning motivation and English learner autonomy. Fig 5 shows the gender-based English learning autonomy scores of high school students, indicating that there is a difference in male and female students' English learning autonomy scores; except for the English learning motivation, male students scored higher than female students in other aspects. Fig 6 shows the English learning autonomy scores of high school students based on English performance. It can be clearly seen that students with excellent performance scored significantly higher in English learning autonomy, and the scores from various aspects of English learning autonomy showed significant differences in English performance. 


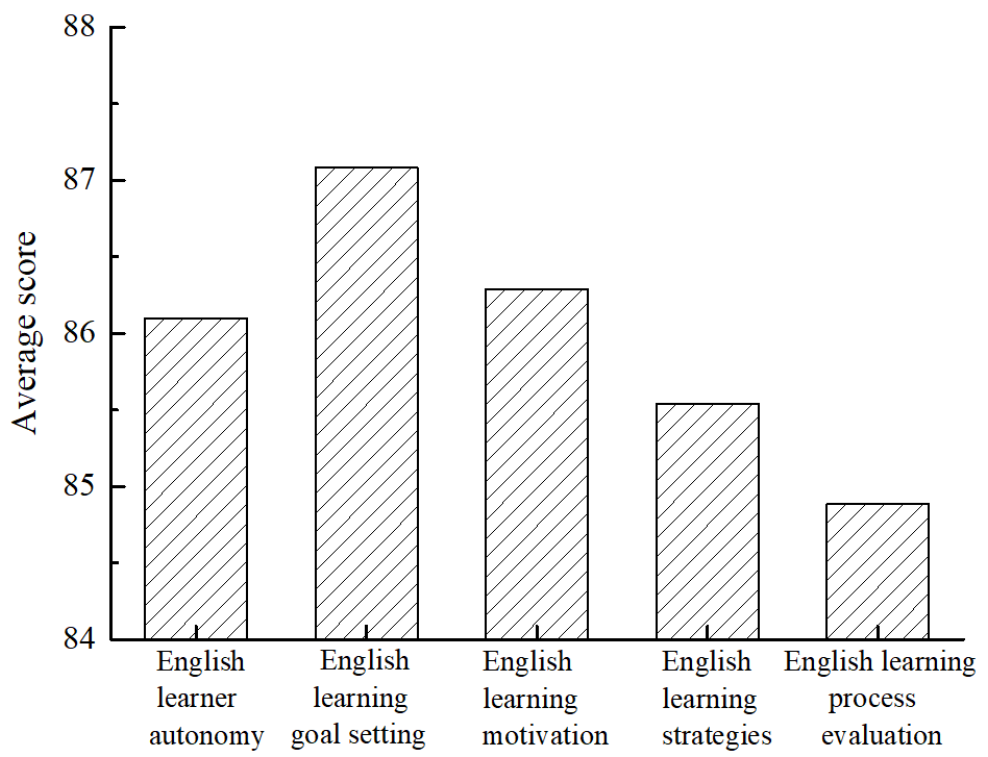

Fig. 4. English learning autonomy score of senior high school students

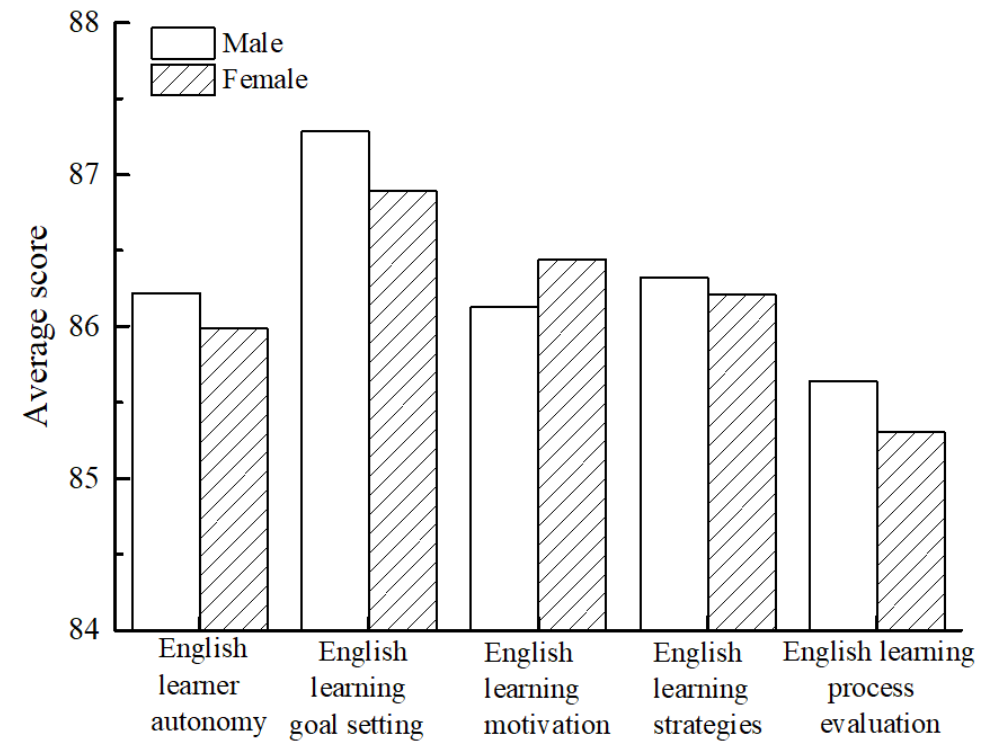

Fig. 5. Gender based assessment of English learning autonomy of senior high school students 


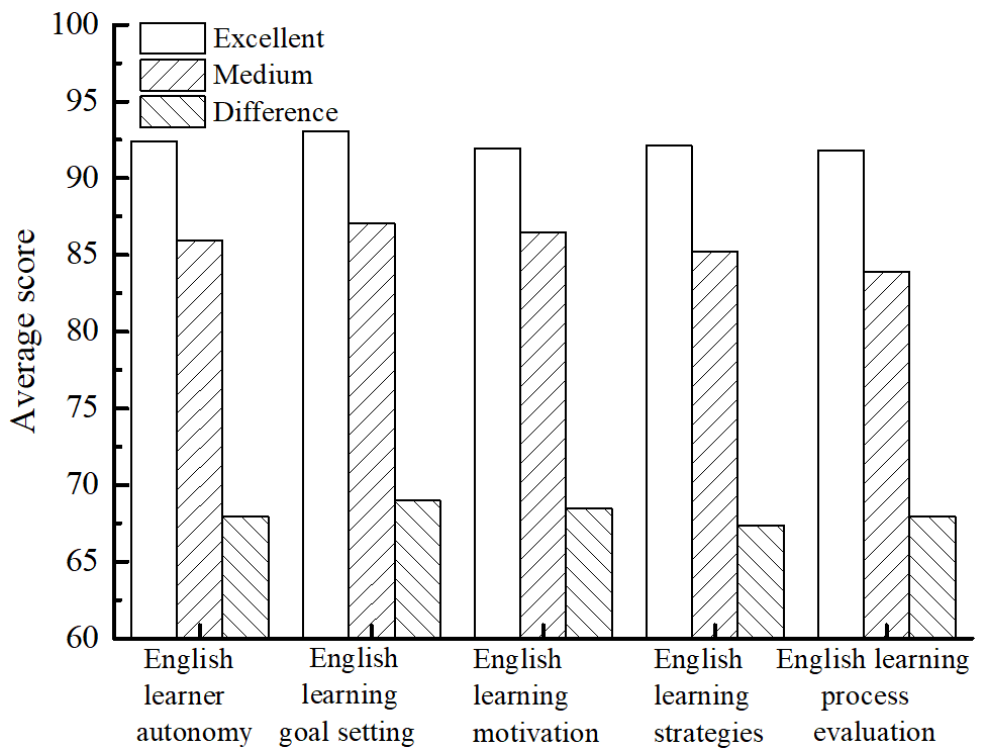

Fig. 6. English learning autonomy score of senior high school students based on learning achievement

\subsection{Discussion on the relationship between self-efficacy and English performance}

Students with low self-efficacy tend to be pessimistic about learning autonomy and learning motivation. English learning efficacy includes three aspects: self-efficacy, behavioural efficacy, and ability efficacy. Fig 7 shows the overall level of English selfefficacy; the self-efficacy scored higher than the behavioural efficacy, and the behavioural efficacy scored higher than the ability efficacy. However, the average score of the overall English learning efficacy did not show a significant difference, while there was a significance difference in the maximum values (the maximum score of the ability efficacy was significantly smaller than the other two), which indicates a significant difference in the efficacy among different students. Fig 8 shows the self-efficacy scores of English learning based on gender differences. It can be clearly seen that male students' self-efficacy and behavioural efficacy were higher than females, while female students' English-learning ability efficacy was higher than males, but there is no significant difference in terms of gender factor. Fig 9 shows the English learning self-efficacy score based on English performance. It can be clearly seen that students with good English performance scored higher in self-efficacy, and there are significant differences in selfefficacy scores in terms of English performance factor. In this paper, students' English learning performance values and self-efficacy scores were subjected to regression standardized residual analysis. The regression relationship between self-efficacy and English performance is shown in Fig 10. It can be clearly seen that there is a significantly positive correlation between the two. 


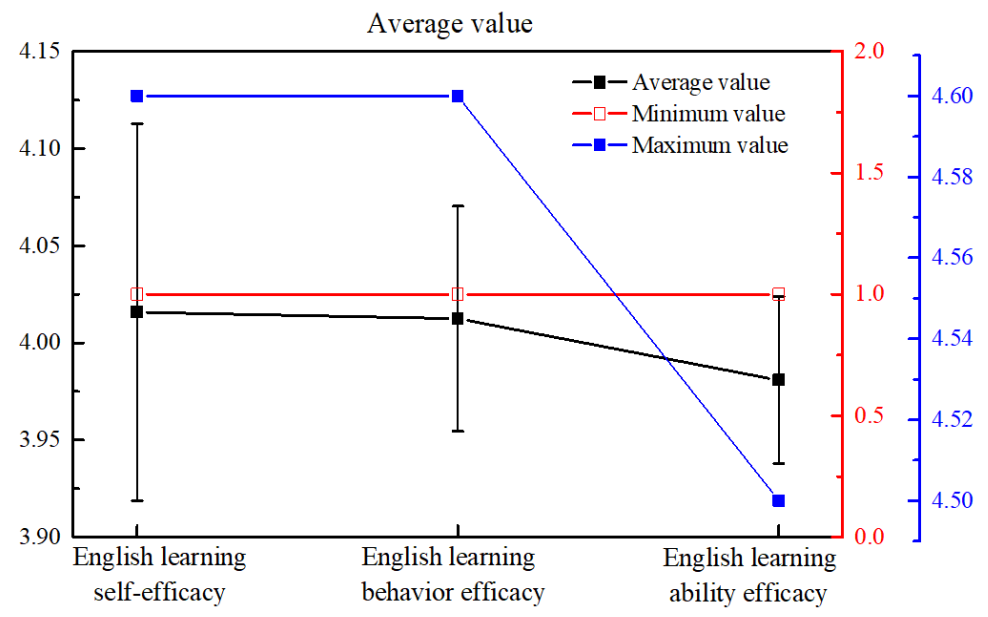

Fig. 7. Overall level of English Self-efficacy

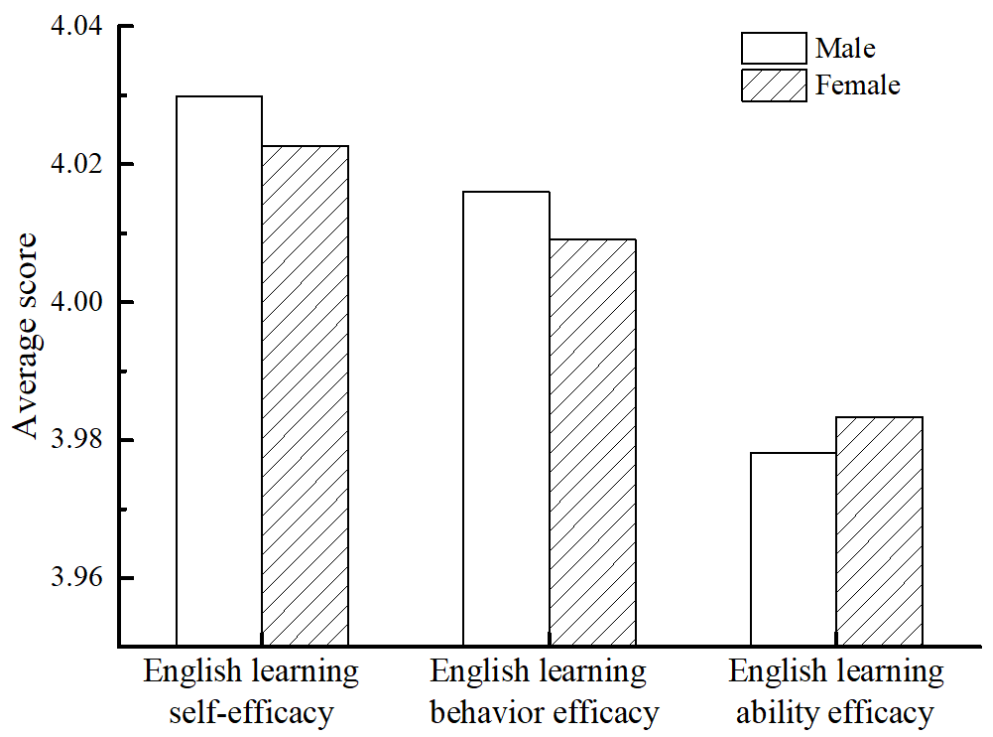

Fig. 8. English learning self-efficacy score based on gender differences 


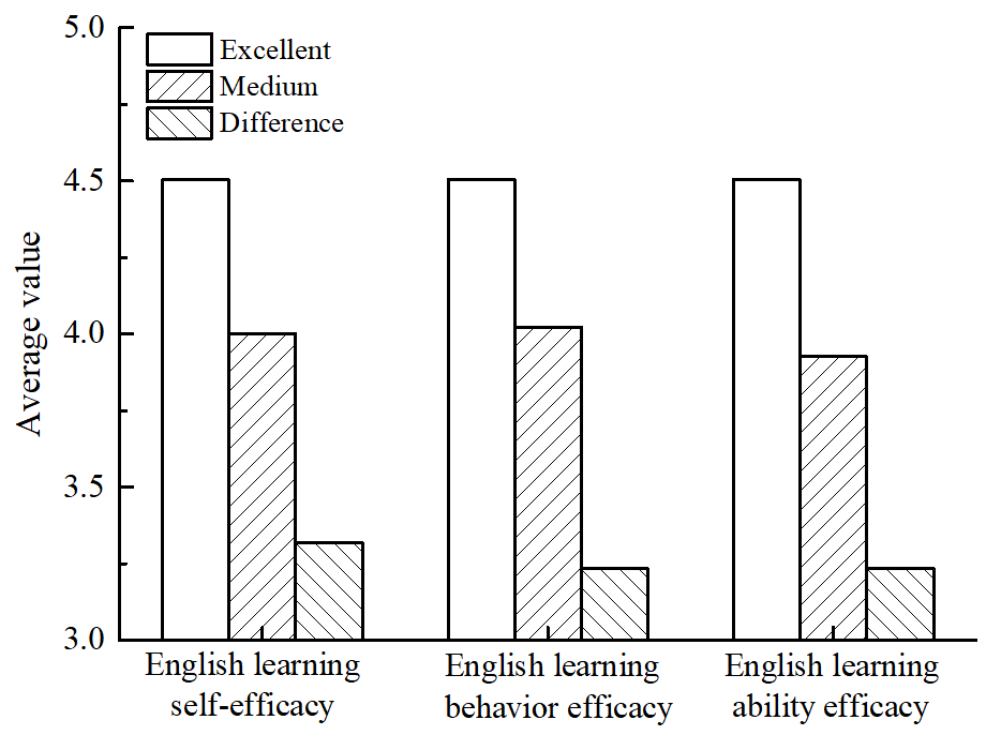

Fig. 9. English learning self-efficacy score based on learning performance

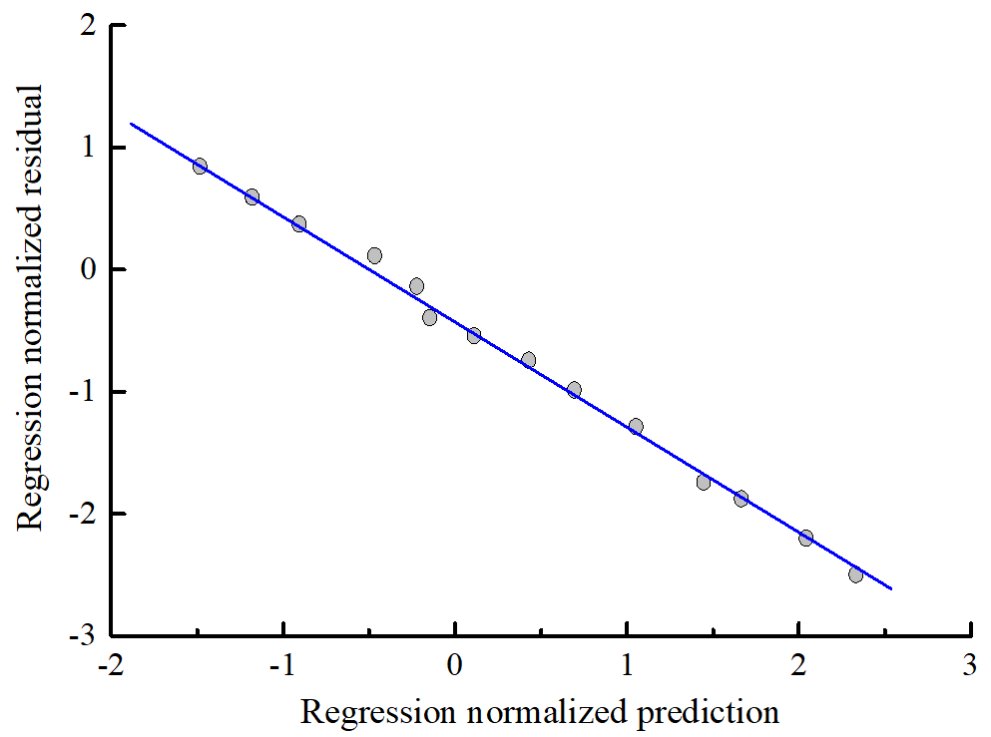

Fig. 10. The regression relationship between self-efficacy and English performance

\subsection{Strategies for enhancing self-efficacy and English performance}

The survey shows clearly that the improvement of self-efficacy is conductive to promoting students' English learning performance. Fig 11 shows strategies for enhancing self-efficacy and improving English performance. Specifically, students should be 
encouraged to set reasonable learning goals and strengthen their sense of achievement in achieving the goals. Furthermore, students should properly treat the learning results and make reasonable attribution, and strengthen English learning strategy training to improve their learning ability. Also, it's necessary to use learning models to motivate students' learning, realize the active use of teachers' persuasion and encouragement by giving play to students' motivation of "self-evaluation", and focus on the relationship between students' psychological state and academic emotions.

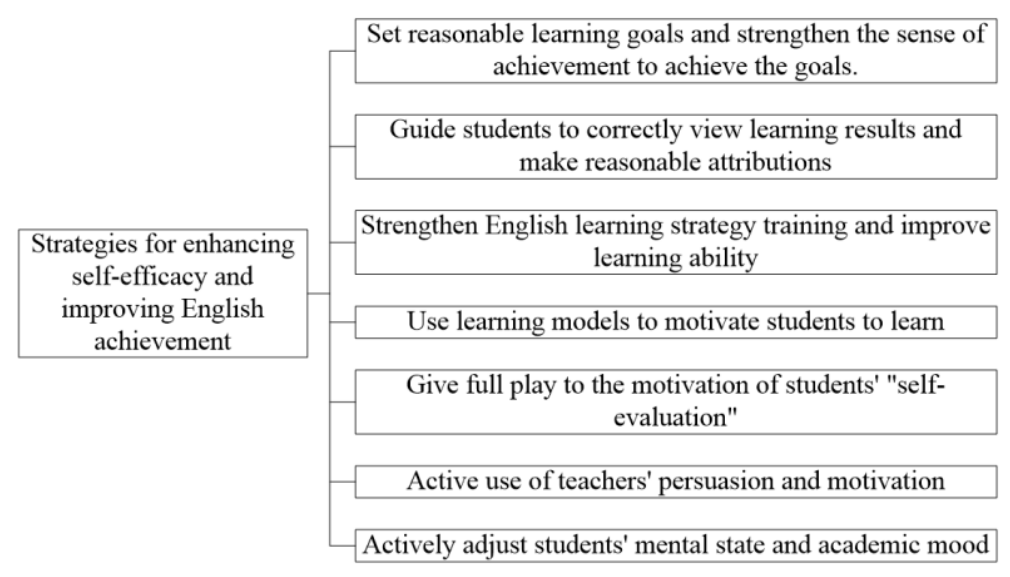

Fig. 11. Strategies for enhancing self-efficacy and improving English performance

\section{Conclusion}

Based on the theory of self-efficacy, this paper explores the impact of self-efficacy on English performance, and deeply studies the internal relationship between the two. The specific conclusions are as follows:

1) Self-efficacy mechanisms include selection processes, cognitive processes, incentive processes, and emotional processes. Self-efficacy affects environmental choices and behaviour choices. Self-efficacy beliefs affect cognitive processes in various ways, and play a major role through the thinking process accompanied by motivational factors or processes.

2) English learning autonomy includes English learner autonomy, English learning goal setting, English learning motivation, English learning strategies, and English learning evaluation. Students with excellent performance scored significantly higher in English learning autonomy, and the scores in all aspects of English learning autonomy showed significant differences in English performance.

3) The sense of efficacy in English learning includes three aspects: self-efficacy, behavioural efficacy, and ability efficacy. Students with good English scored higher in terms of self-efficacy scores, and there is a significantly positive correlation between self-efficacy and English performance. 


\section{$6 \quad$ References}

[1] Sun, J., Chang, K. Y., Chen, Y. H. (2015). GPS sensor-based mobile learning for english: an exploratory study on self-efficacy, self-regulation and student achievement. Research \& Practice in Technology Enhanced Learning, 10(1): 23. https://doi.org/10.1186/s41039-0150024-y

[2] Ritter, P. L., \& Lorig, K. (2014). The English and Spanish self-efficacy to manage chronic disease scale measures were validated using multiple studies. Journal of Clinical Epidemiology, 67(11): 1265-1273. https://doi.org/10.1016/j.jclinepi.2014.06.009

[3] Alagozlü, N. (2016). Pre-service EFL teachers? professional self-concept: English teaching efficacy, self reported English proficiency and pedagogical strategies: a case study in turkish context. Procedia - Social and Behavioral Sciences, 232: 196-200. https://doi.org/10.1016/j.sbspro.2016.10.045

[4] Ghasemboland, F., Hashim, F. B. (2013). Teachers' self-efficacy beliefs and their English language proficiency: a study of nonnative EFL teachers in selected language centers. Procedia-Social and Behavioral Sciences, 103: 890-899. https://doi.org/10.1016/ j.sbspro.2013.10.411

[5] Kücüktepe, S. E. (2010). A study on preservice English teachers' self-efficacy perceptions and tendency towards academic dishonesty. Procedia-Social and Behavioral Sciences, 2(2): 4985-4990. https://doi.org/10.1016/j.sbspro.2010.03.807

[6] Moghari, E. H., Lavasani, M. G., Bagherian, V., Afshari, J. (2011). Relationship between perceived teacher's academic optimism and English achievement: role of self-efficacy, 15: 2329-2333. https://doi.org/10.1016/j.sbspro.2011.04.102

[7] Chularut, P., DeBacker, T. K. (2004). The influence of concept mapping on achievement, self-regulation, and self-efficacy in students of english as a second language. Contemporary Educational Psychology, 29(3): 248-263. https://doi.org/10.1016 ji.cedpsych.2003.09.001

[8] You, S., Dang, M., Lim, S. A. (2016). Effects of Student Perceptions of Teachers' Motivational Behavior on Reading, English, and Mathematics Achievement: The Mediating Role of Domain Specific Self-Efficacy and Intrinsic Motivation. Child \& Youth Care Forum, 45(2): 221-240. https://doi.org/10.1007/s10566-015-9326-x

[9] Huang, F., Hoi, C. K. W., Teo, T. (2018). The influence of learning style on english learning achievement among undergraduates in mainland China. Journal of Psycholinguistic Research, 47(5): 1069-1084. https://doi.org/10.1007/s10936-018-9578-3

[10] Yang, J. C., Quadir, B. (2018). Individual differences in an english learning achievement system: gaming flow experience, gender differences and learning motivation. Technology Pedagogy \& Education, 27(3): 351-366. https://doi.org/10.1080/1475939x.2018.1460618

[11] Shukor, N.A., Abdullah, Z. (2019). Using learning analytics to improve MOOC instructional design. International Journal of Emerging Technologies in Learning, 14(24): 6-17. https://doi.org/10.3991/ijet.v14i24.12185

[12] He, T., Gou, W. J., Chang, S. M. (2015). Parental involvement and elementary school students' goals, maladaptive behaviors, and achievement in learning English as a foreign language. Learning and Individual Differences, 39: 205-210. https://doi.org/10.1016 j.lindif.2015.03.011

[13] Kuo, F. R., Hsu, C. C., Fang, W. C., Chen, N. S. (2014). The effects of embodiment-based TPR approach on student English vocabulary learning achievement, retention and acceptance. Journal of King Saud University - Computer and Information Sciences, 26(1): 63-70. https://doi.org/10.1016/j.jksuci.2013.10.003 
[14] Lu, X. H., Zhang, J. B. (2012). College students' use of the computer and network-based self-access centre and their English learning achievement. IERI Procedia, 2: 149-154. https://doi.org/10.1016/j.ieri.2012.06.066

[15] Wang, C., Harrison, J., Cardullo, V., Xi, L. (2017). Exploring the relationship among international students' English self-efficacy, using English to learn self-efficacy, and academic self-efficacy. Journal of International Students, 8(1): 233-250. https://doi.org/10.32674/jis.v8i1.163

[16] Wang, C. K., Kim, D. H., Bong, M., Ahn, H. S. (2013). Examining measurement properties of an English self-efficacy scale for English language learners in Korea. International Journal of Educational Research, 59: 24-34. https://doi.org/10.1016 /j.ijer.2013.02.004

[17] Zhang, X., Ardasheva, Y., Egbert, J., Ullrich-French, S. C. (2019). Building assessments for self-efficacy in English public speaking in china. The Asia-Pacific Education Researcher, 28(5): 411-420. https://doi.org/10.1007/s40299-019-00441-9

[18] Wahed, W.J.E., bin Husain, A.H., Wahed, W.J.E., Pitil, P.P. (2019). The influence of Artist in Schools (AiS) program and the ARCS motivational model on students' creativity and motivation in visual art. International Journal of Emerging Technologies in Learning, 14(20): 149-156. https://doi.org/10.3991/ijet.v14i20.11464

\section{$7 \quad$ Author}

Yinchun Chen was born on 4th, April, 1980 in Huanggang City, Hubei Province, China. She received B.A. degree of English from Yanshan University in 2003 and M.A degree in English Language and Literature from Yanshan University in 2008. She started her teaching career in July, 2003 in Yanshan University. Since 2003, she has authored more than 10 papers in English teaching, literature and translation. She has participated in compiling several textbooks and CET4 tutorials, authored a book Innovative Development and Research of English-Chinese Translation in Crosscultural Context, participated in a state project and hosted a municipal research project.

Article submitted 2020-02-23. Resubmitted 2020-04-02. Final acceptance 2020-04-04. Final version published as submitted by the authors. 